\title{
Cross Discipline Technology Integration
}

\author{
Janet Holland \\ Emporia State University, USA
}

\begin{abstract}
Instructional Design and Technology is a natural platform for cross discipline studies. With almost every field today using technology for teaching or training it is a natural fit. At our University, in our department we have students with a wide range of professional interests all needing to find effective ways to teach their content area to others. Even our own University has requested our department's assistance in training colleagues from all discipline areas across campus to assist with integrating technology into their classes. Through the integration of technology it is a great way to cross discipline to any content area.
\end{abstract}

\section{Introduction}

Working as a college professor of both preservice teachers on campus and online Master's Degree students in the field of Instructional Design and Technology we are embracing the increasing global diversity of students in our classrooms. In fact, we are working hard to find effective ways to harness the expanded global perspectives to maximize learning opportunities in our classrooms. The field of technology is unique in its ability to offer a powerful bridge for crossing disciplines with any content area of interest. The combined increased diversity in students' personal knowledge and experiences and diversity of academic and professional goals broadens the overall perspectives offered and increases learning opportunities for all learners. Many students have stated how they are seeing a broader global perspective of the field and can now see cross discipline intersection points between different fields of study through Instructional Design and Technology. They feel better prepared to teach or train and capitalize on the benefits of cross discipline instructional practices. Selecting appropriate technologies can assist in facilitating the needed collaboration, teamwork, and dialogue needed for sharing expanded perspectives and disciplines for solving complex problems.

\section{Cross Discipline}

Crossing disciplines and examining how they intersect is a great way to see the "big picture perspectives needed to deal with complex problems and issues that resist standard disciplinary resolutions" [4]. Rather than viewing issues through a single discipline, it requires looking at broader interdisciplinary perspectives, how they cross, compare, borrow, integrate, or even transdiscipline completely new methods. Cross discipline studies is a way to "provide critical bridges among diverse schools of thought, helping students experience firsthand the interplay among the academic disciplines and how that interaction broadens our thinking and approaches to problem-solving” [6]. Cross discipline studies allows learners to "produce something much higher and more creative" especially when "going beyond the aggregation of insights from different disciplines by integrating them" [15]. In essence, facilitating a comprehensive understanding to solve complex problems. When researching the literature for cross-discipline studies one may need to expand the search terms examined to include interdiscipline, multidiscipline, and transdiscipline. Interdiscipline studies often refer to solving complex problems requiring more than one discipline perspectives. Multidiscipline is often used for comparing two or more disciplines. Transdiscipline is considered a more comprehensive high-level synthesis of different disciplines applied to ideas or methods. By implementing small crossdiscipline challenges, teams have the potential of reaching high levels of performance.

\section{Cross Discipline Instructional Technology Tools}

With the massive and rapid expansion of new digital tools it has become very difficult to keep pace with the ever changing instructional design landscape. By sharing we can expand our repertoire of relevant digital tools in light of the instructional benefits offered to learners. Selecting digital tools offering multiple modes of acquiring information, communicating, collaborating, analyzing, and presenting expands learners abilities to understand and find innovative solutions. Having learners 
construct knowledge through authentic active inquiry-based exploration of problems follows current best instructional practices. It can be used to build a solid foundation for thinking, reasoning, and learning, so students will be able to effectively resolve complex issues as they are presented. Implementing case studies, theme based, and problem based lesson structures are good ways to capitalize on high level thinking skills needed to address challenging problems. Presenting learners with authentic real world issues can add an additional motivational spark for in depth research and analysis. With the tremendous growth of new technology tools available, collaborating and solving authentic problems across disciplines and across the globe is becoming much easier. Technology supported cross-discipline studies using a wide variety of media are a great way to infuse lessons with "varied teaching techniques to capture the interest of a diverse student population" [6]. The digital tools selected should capitalize on facilitating talent to reach the desired objectives. Modern digital tools have moved beyond number crunching alone to include visual design strategies for building multiskill sets needed for creativity and innovation. Some of the best categories of digital tools used to facilitate cross discipline studies are provided as follows. They include graphic organizers, research, pre- and postassessment, collaborative, and presentation tools.

\section{Cross Discipline Globalization}

The modern world is becoming more diverse as we transition towards global learning environments. By fostering an appreciation for our differences we will be able to interact productively as groups with all people from all discipline areas. By capitalizing on divergent experiences we can expand our perspectives and begin to promote reflective dialogue towards finding unique solutions to challenges presented. Effective collaborative efforts facilitated through the use of current digital tools can assist in guiding learners to prepare for the reality of globalization in all discipline areas both in classrooms and the work environment. The best current digital tools used for facilitating global learning experiences focus on communications and collaborations. Current digital tools encouraging collaboration help us shift towards a participatory model of international exchange. It includes synchronous learning environments and asynchronous digitally mediated international exchanges. Both formats help to "expose students to different ways of thinking” [9]. Deeper, higher level, more comprehensive analysis through multiple perspectives can assist learners in fostering creative and comprehensive solutions to issues addressed. "Consideration of diverse perspectives is essential as we educate students for life in a future where national boundaries will be blurred by global imperatives" [8].

Global knowledge skill sets should include authentic problems, conducting needs analysis, researching, debating, collaborating, synthesizing, analyzing, reflecting, revising, and presenting possible solutions. An important component also includes teaching intercultural skills for working together effectively through an appreciation and acceptance of the wide range of values, cultures, and talents each team member brings to the group. The acceptance of differences and diversity in all the team members is an important step needed to gain cultural sophistication. Capitalizing on diverse talents through successful interactions helps to prepare learners to be connected, responsible, and productive by building on their combined strengths.

With the ability to digitally share text, images, whiteboards, and audio video conferencing without limitations on times and places, international exchanges are becoming more transparent. International exchanges, when properly focused, can serve as the catalyst for building knowledge globally. Widened perspectives enrich knowledge acquisition and combined team efforts can accelerate the pace. Instructors and trainers have the opportunity to leverage globalization to capture knowledge, synergy and innovation needed to adapt to changing conditions in education and in the workplace.

\section{Cross Discipline Collaborations}

Group work or teamwork collaborations have become an integral part of today's classrooms and work environments as a way to work together effectively and efficiently. Teamwork is a basic skill used to accomplish mutual goals and objectives. Much of the research cites cases of increased learning, productivity, and satisfaction stemming from "team spirit, work ethic, and equal team member contributions” [10]. There are many digital tools to select from for promoting collaborative efforts for authentic meaningful group interactions. To respond to the "need for increased team productivity and the present need for students to come into the workforce with effective interdisciplinary team skills" implementing teamwork using collaborative technologies provides an elegant solution unbounded by time and place [10]. Teamwork can be used to capitalize on the synergy of collaborating with peers for social support, expanded perspectives, increased knowledge capital, and finding innovative solutions. Using diverse teams can add another layer of enlarged global perspectives.

Collaboration can be implemented to leverage creativity and teamwork. Research has demonstrated potential benefits in areas of increased productivity, learning, higher levels of effectiveness, and 
personnel satisfaction when designed appropriately with clear goals, policies, time allowed, and shared contributions. It can begin with team building, so the needed social foundation is in place before beginning the workflow process. Cultivating trust and building the social capital first promotes the needed relationship building for effective team communications. When working in teams it is important to build effective communications and tolerance for the different ideas brought forth. Rewarding teams for working together effectively and efficiently can go a long way towards ensuring long-term success.

Having groups brainstorm together, they can identify issues quickly, while researching and formulating potential solutions at a much quicker combined pace. Keeping the team sizes small can keep the communications at a more manageable level. Using cross discipline teams can assist in keeping perspectives broad so all can see the big picture issues. By selecting the best technology tools for the job they can be used to leverage the team knowledge assets. Some of the organizational team issues can then include goal setting, measuring the team's progress, and having success dependent upon the group success.

\section{Cross Discipline with Web 2.0 Tools}

Integrating Web 2.0 tools into instruction can be a great way to promote cross discipline studies. Web 2.0 tools can be used to "embrace and promote new learning environments" [3] for students through active participation in locating, researching, discovering, communicating, collaborating, sharing, innovating, creating, evaluating, building information literacy, and self publishing [7]. Many of the collaborative communication tools can be used to increase knowledge and connect learners from around the globe. "Students partaking of this rich international conversation find themselves catapulted beyond the physical boundaries of the classroom" [1]. Providing meaningful integration of new technologies can "revolutionize the way students and teachers engage with concepts, collaborate with one another, and use digital literacies” [11].

Web 2.0 tool selection options can vary widely. It will be up to you, the facilitator, to determine the primary learning objectives by which to narrow the search and make the final selections for the desired digital tools. Cross discipline lesson plans integrated with Web 2.0 tools requires a mixture of vision and excitement to engage and challenge student learning. "The new generation of Web 2.0 solutions are easier to use, more engaging and are making a larger impact upon collaboration and communication in the classroom" [14]. Part of the challenge is finding innovative ways to bring together instructors, students, mentors, and experts for social scholarship to create the "cyberinfrastructure needed for increased innovation, globalization, and knowledge networking” [5]. Web 2.0 learning environments providing opportunities for collaboration can change the "way learners can retrieve, share and evaluate information, and create knowledge [2]. By designing learning challenges within the social environment we can promote cognitive engagement through the coconstruction of knowledge and exchange of ideas. By making learning interesting, fun, and challenging it is a great way to capture students' imagination and passion for the topic and continued learning.

A good starting place for online lesson planning is to begin with an analysis of learner needs, goals and objectives, while aligning the content and tools selected for engaging student learning. Quality instructional practices often include an intellectual challenge through authentic, interactive, collaborative, generative, inquiry, problem-based learning opportunities to assist students in thinking critically about the content. Many of the current Web 2.0 tools align perfectly for creating compelling learning opportunities for students. Teaching students to "effectively and creatively find, evaluate, analyze, use, and communicate information" initiates important lifetime skills [13].

The following online resources can be used for helping instructors and students to select the type of Web 2.0 tool to best match the desired learning goals. Based on a derivation of Bloom's Taxonomy Model for higher-level thinking skills by author Samantha Penney, from the University of Southern Indiana (2010) includes the main categories of 1) creating, 2) evaluating, 3) analyzing, 4) applying, 5), understanding, and 6) remembering. Below is an example of the model in text form with the Web 2.0 tools applied. The online pyramid from Krathwohl and Anderson (2001) is an adaptation of Blooms Taxonomy (1956). Using this as a guide is one way to begin selecting appropriate Web 2.0 tools for targeted instructional learning goals. This list is a great beginning point for analyzing the tool options. Many additional tools could be included in this list. However, it is important to keep in mind some tools could be placed into more than one area depending on how each is used.

\section{Creating}

Web 2.0 Tools: Prezi, Voicethread, Protagonize, Glogster Edu, Wikispaces

2. Evaluating

Web 2.0 Tools: RubiStar, YouTube, PollDaddy, iRubric, Protagonize, Rcampus, E Portfolio, Survey Monkey, Nota

3. Analyzing

Web 2.0 Tools: iExploratree, Google Analytics, Google Trends 10x10, Google 
Finance, Create a Graph, Pipes, Google Earth

4. Applying

Web 2.0 Tools: WolframAlpha, Google Sketchup, Go2Web20.net, Scribble Maps, Gliffy, Evernote, Pipes

5. Understanding

Web 2.0 Tools: The Periodic Table of Videos, Wikipedia, Google News Timeline Labs, Footnote, Webspiration, JeopardyLabs, JohnLocker.com, SlideShare, Bubbl.us

6. Remembering

Web 2.0 Tools: Technorati, Wordnik, FlashcardExchange, Creately, NinjaWords, CoboCards, Visuwords online graphical dictionary, CarrotSticks, Zoho Work Online, LinoIt, Delicious, Flickr

Permission Granted:

Samantha P. (2010). Bloom's Taxonomy of Web 2.0 Tools. University of Southern Indiana.

One of the graduate students in our program at Emporia State University took the concept of Bloom's Digital Taxonomy one step further to use it as a basis for linking to related Web 2.0 tutorials as an instructional technologist working in the K-12 setting for teacher training. The categories used included 1) creating, 2) evaluating, 3) analyzing, 4) applying, 5) understanding, and 6) remembering. The digital tool tutorials are listed below.

1. Creating: Animoto, Google Sites, Voki, VoiceThread.

2. Evaluating: EduBlogs, Wordpress Blogs, Bubbl.us Collaborative Mapping, Google Earth, Twiddla Collaborate Wkspace.

3. Analyzing: Wordle, Survey Monkey, OmniGraffe, Facebook, Delicious Bookmarking, Digital Graphic Organizers.

4. Applying: Games, Flickr, SchoolTube, Glogster, Go2web20.net

5. Understanding: Google WonderWheel Search, Diigo, iTunes, Lucid Outliner, Online Summarizing Tool.

6. Remembering: Visual Thesaurus, Stixy, Wallwisher, Internet Flashcard Database, MindMap.

Permission Granted:

Leimbach, L. (2010). Bloom’s Mashup: Bloom's Taxonomy Tools and Tutorials. Teacher Tech: Changing Education One Byte at a Time.
The Stripling Inquiry-Based Model (2010) was designed as a student centered framework for learning. It includes six main phases of student generated critical thinking, including; 1) connect, 2) wonder, 3) investigate, 4) construct, 5) express, and 6) reflect. Below is a condensed example of the approach combined with some Web 2.0 tool examples added to assist in making tool selections for teaching and learning. Again, many additional tools could be added to this list or some could be included in more than one category. Below is a copy of the Inquiry and Web 2.0 Tools Integration Guide.

1. Connect: Observe, experience, connect a subject to self and previous knowledge. Teaching Strategy: Dialogue, research, journal, log, chart, organizer, engage, explore.

Web 2.0 Tools: EduBlogs, Ning, Wikispaces, Skype, Google Docs, Zoho Suite, Mindmeister, Bubbl.us, Mind42, LooseStitch, Google Earth, TeacherTube, Flickr

2. Wonder: Predict, develop questions and hypotheses.

Teaching Strategy: Brainstrom, questioning, anticipation guides.

Web 2.0 Tools: Google Docs, templates, Mindmeister, Bubbl.us

3. Investigate: Find and evaluate information to answer questions, test hypotheses.

Teaching Strategy: Research, notes, guided practice, organize, evaluate.

Web 2.0 Tools: Google, Clusty, Ask, Kartoo, Exalead, Intute, Google Docs, Zoho Notebook, iOutliners, SpringNote, Wikispaces (pathfinders), Jing, Voicethread, Google Reader, Diigo, Delicious, SimplyBox, Netvibes, Pageflakes, 30 Boxes, TaDaList, Mindmeister, Bubbl.us

4. Construct: Conclusions, arrive at new understandings.

Teaching Strategy: Chart, map, compose, question.

Web 2.0 Tools: Edublogs, Wikispaces, PBWorks, GoogleDocs, Zoho Suite, Polleverywhere, Google Docs, Zoho Suite, Edublogs, E-mail, Instant Messenger, Skype, Twitter

5. Express: Apply understanding to a new context, share learning with others. Teaching Strategy: Rubric, conferencing. Web 2.0 Tools: Google Docs, Zoho Suite, 
Voicethread, Glogster, Podcast, Animoto, Flickr, TeacherTube, Skype, Blogs, Nings

6. Reflect: Examine one’s own learning and ask new questions.

Teaching Strategy: Feedback, reflection log: I use to think, now I know.

Web 2.0 Tools: EduBlogs, Wikispaces, Email, Ning, GoogleDocs, Voicethread, Podcast

Permission Granted:

Berger, P. \& Stripling, B. (2010). Student inquiry and Web 2.0. School Library Monthly, Greenwood Publishing Group Inc. Vol XXVI, Vol. 5, Jan.

For including Web 2.0 websites in the K-12 learning environment The American Association of School Librarians has listed their top 25 sites for teaching and learning. Again, many additional websites could be added to the list but it provides a good starting place for selecting and testing sites to meet your specific learning needs.

1. Media Sharing Websites

Web 2.0 Tools: Glogster, Masher, Prezi, Professor Garfield, SchoolTube, Scratch, WatchKnow.org

2. Digital Storytelling Websites Web 2.0 Tools: International Children's Digital Library, Jing, Storybird

3. Manage and Organize Websites Web 2.0 Tools: Evernote, Jogtheweb, Live Binders, MuseumBox, Pageflakes, Weblist

4. Social Networking and Communication Web 2.0 Tools: Creative Commons, Learn Central, TED

5. Content Collaboration Websites Web 2.0 Tools: Debategraph

6. Curriculum Sharing Websites Web 2.0 Tools: Exploratree, The Jason Project, National Science Digital Library

7. Content Resources: Lesson Plans and More Websites

Web 2.0 Tools: Edsitement, National Archives Digital Classroom

Permission Granted:

American Association of School Librarians (2010). Best websites for teaching and learning: Top 25 websites for teaching and learning.

Below are some Web 2.0 online supplemental resource sites for finding new Web 2.0 tools and websites for integrating into online teaching and learning.

- Bloom's Taxonomy of Web 2.0 Tools (2011). http://www.usi.edu/distance/bdt.htm (8 March 2011).

- Bloom's Taxonomy Tools and Tutorials (2011). http://lleimbach.glogster.com/blooms-resources andhttp://rsu2teachertech.wordpress.com/2010/12/04/b looms-mashup/ (8 March 2011).

- Inquiry and Web 2.0 Tools Integration Guide (2011).http://www.schoollibrarymonthly.com/articles/ Berger2010-v26n5p14.html (8 March 2011).

- Top 25 Websites for Teaching and Learning (2011).http://ala.org/ala/mgrps/divs/aasl/guidelinesand standards/bestlist/bestwebsitestop25.cfm (8 March 2011).

- Web 2.0 Cool Tools for Schools (2011). http://cooltoolsforschools.wikispaces.com/ (8 March 2011).

- Go2Web20 (2011). http://www.go2web20.net/ (8 March 2011).

- $\quad$ Top 15 Most Popular Web 2.0 Websites (2011). http://www.ebizmba.com/articles/web-2.0-websites (8 March 2011).

- Teaching with Technology (2011). Tools for Creating, Editing, and Sharing: http://ipt286.pbworks.com/w/page/10618966/Index (8 March 2011).

- SlideShare (2011). Top 20 Web 2.0 Tools for Teachers and Librarians: http://www.slideshare.net/scyuen/top20-web-20-tools-for-teachers-and-librarians (8 March 2011).

- $\quad$ Centre for Learning \& Performance (2011). Top 100 Tools for Learning 2010 List (2011). http://www.c4lpt.co.uk/recommended/top1002010.html (8 March 2011).

- Internet 4 Classrooms: Web 2.0 Tools (2011). http://www.internet4classrooms.com/web2.htm (8 March 2011).

- ISTE Wikispaces: Favorite Web 2.0 Tools (2011).

- http://sigilt.iste.wikispaces.net/Favorite+Web+2.0+Too ls (8 March 2011).

- Web 2.0 Guru: Web 2.0 Resources for $21^{\text {st }}$ Century Instruction (2011).

- http://web20guru.wikispaces.com/Web+2.0+Resources (8 March 2011).

Discovery Education: Web 2.0 Tools (2011). http://school.discoveryeducation.com/schrockguide/edt ools.html (8 March 2011).

\section{Cross Discipline Web 2.0 Pilot with VoiceThread}

One of my synchronous on campus pre-service teacher courses became a perfect candidate for an initial classroom test pilot using a Web 2.0 technology called VoiceThread [12]. Most of the pre-service teachers in the course were planning to work in elementary level classrooms upon completion of their degree programs.

My pre-service teachers used VoiceThread to create lesson examples for their future students. VoiceThread was found to be a great way for 
instructors to model the concepts to be taught using both images, text, voice, and the drawing board directed towards the desired learning standards. The teachers worked to make the lessons more interactive for the students by asking probing questions and posing learning challenges to extend content learning even further. A number of the topics the pre-service elementary teachers selected to present on included Geography, Science, Art, Literature, Math, History, and Culture. The subsequent lessons were specifically designed to meet state standards while combining the use of KidPix for the illustrations and VoiceThread for the audio-visual examples, demonstrations, and communications. Based on the initial pilot test, it was easy to see any content area could be integrated for cross discipline studies.

The teachers also created a website to hold additional lesson information, such as the introduction, examples, instructions, practice activities, lesson activities, resources, and assessment rubrics. The pre-service teachers felt the combination of using VoiceThread and KidPix was a good way for students to take abstract concepts and make them more concrete by having students create their own images using their own voices to communicate concepts while including their own personal experiences.

By using a combined mixed media tactic, it was found to have the added value of even richer learning experiences. For example, in the past teachers developed an art lesson for their students using a digital art program to create their own artwork. The teachers could then use the lesson developed for authentic hands on learning experiences for their students while combining the project with any content area of interest to be taught. Even though the content had depth, the project itself was onedimensional, in that when completed the learning ended. By taking it one step further and displaying the student work on VoiceThread it opens up a whole new dimension, with the students providing their own story and voice reflections on the learning process. In addition, the instructor, classmates, family, friends, and the global learning community are able to add comments and questions to extend the content, and support learners' efforts.

Through the pilot and viewing additional external online examples, it clearly demonstrated how instructors could use VoiceThread in the classroom for active multimodal engaged authentic inquirybased learner critiques, explanations, analysis, interpretations, demonstrations, reports, presentations, debates, collaborative interactions, practice, and motivation. Learners can create digital narratives and documentaries while developing their personal voice and creating their own portfolio of work. It is an ideal environment for differentiated instruction and inquiry-based learning applied to any content area of interest. Instructors can also post video lectures, podcasts, slides, notes, demonstrations, and learning challenges for students with the ability to ask additional questions, and post responses.

One of the technological advantages found when using the VoiceThread technology is how the media options are extended through the use of multiple channels at one time. Instead of pure text-based chat or whiteboards used individually and separately, these features are combined in one place with the addition of audio. This multi-media approach opens up the possibility of reaching more diverse student populations and learning preferences. Online interactions become more authentic, interactive, and immersive for student participants through written words, drawing, images, and personal audio narratives. Online communications become more natural and accessible to student learners and support multimodal collaborative teaching and learning practices.

To begin creating your own VoiceThread, go to their website and register for an account, then sign in. You can browse existing VoiceThread productions as a resource or they can be used as way to brainstorm additional ideas on how you might be able to use and implement this Web 2.0 tool for your own productions. By selecting the top browse button it will take you to the browse page. From there, you will find a top browse search box for typing in the desired topics to begin narrowing the search results.

To begin creating your own page, select the create tab along the top and it will take you to a page where you can select the upload link to bring in your images, documents, or videos from your computer, media source, or from a website address. After uploading the desired media, the next step is to select the comment link, then from the media window select the second comment link below the media to be able to edit. You will be able to record, type, or use a webcam to record a video, or make a comment by phone. To record your own voice simply select the record button and begin talking. When you are finished, press the stop recording button. Press the save button to save the recording. Or, if you make an error, press cancel and you may record again. To listen to your recording, press the personal icon on the left side of the media. With your media and voice recorded, select the share button and you will see several options. If you select the publishing options along the bottom you can make the VoiceThread open to the public, if desired. Since we used teacher recordings delivered to students, this is the option we selected to allow anyone to view comments, and save the setting. Another share option is the link along the bottom called "embed" to place the VoiceThread directly into a web page. From the embed window, highlight the embed code in the text box, select the copy button, and the done button. If you are embedding the VoiceThread into a web page using a 
web authoring program, switch to the Code view, click between the body tags and go to Edit>Paste. Then, switch to Design view and save the page. Next, go to File>Preview in Browser to test before uploading the page to the server. Or, if you do not want to embed VoiceThread into a web page from the share page, select the get a link button and then the copy the link button. The classroom teachers, in the pilot, elected to allow anyone to view and comment so it would be open to the public for anyone to view. Before leaving the create window, select add a title and description link. Then, from the tabs along the top, select "my voice" to be able to view it. Each VoiceThread has a small thumbnail and in the lower right corner you will find a menu with a wheel icon. By selecting the menu you will find additional editing options.

If you need any additional assistance when you login to VoiceThread, look along the top of the window to find the support link. There you will find "how to" answers for frequently asked questions, manual tutorials, discussion support, and contact information if needed. In addition, from the top "community" link you can find a library database, user shared resources, user discussion link, and press publication links. The top "about" link has some great product information details to assist you on issues such as accessibility and many more. The top "product" link will take you to information related to $\mathrm{K}-12$, higher education, business, and professional accounts. Remember, YouTube also has excellent tutorials, if needed to support your efforts.

Based on the initial pilot study it was easy to see how beneficial it is to integrate Web 2.0 technologies into the classroom to promote cross discipline studies with any content area of interest. Even though the pilot was directed towards the elementary classroom instruction it could easily be modified and adapted for middle school, high school, college, or working professionals.

\section{Conclusion}

To begin the process of technology infused cross discipline studies it begins with an informed analysis of the learner needs and instructional goals. Then, appropriate technology resources can be aligned to design quality teaching and learning experiences. It is important to teach learners to effectively select appropriate resources, seek out multiple comparisons for cross checking the sources, content, and analysis of the research. With the massive and increasing number of Web 2.0 tool choices available, it can be a bit overwhelming just trying to decide where to start. Having a good organizational plan, and list of quality resources helps make the needed selections.

Making the effort to include cross discipline studies can pay off by broadening perspectives and synthesizing the best information from each field.
Cross discipline studies really shines through the subsequent integration for building comprehensive understandings to solve complex problems requiring innovative solutions. Cross discipline studies do not have to be limited to two disciplines but rather offers opportunities for multiple discipline research, if desired. After you get the chance to observe and experience many of these tools in use, you will understand why it is easy to anticipate some of the most innovative teaching, learning, and workplace solutions will rise out of such diverse, cross discipline, technology infused collaborative efforts.

\section{References}

[1] Alexander, B. (2008). Web 2.0 and emergent multiliteracies. Theory Into Practice, Lawrence Erlbaum Associates, 47:150-160. American Association of School Librarians (2010). Best websites for teaching and learning: Top 25 websites for teaching and learning, http://ala.org/ala/mgrps/divs/aasl/guidelinesandstandards/b estlist/bestwebsitestop25.cfm (8 March 2011).

[2] Benson R., \& Brack C. (2009). Developing the scholarship of teaching: What is the role of e-teaching and learning? Teaching in Higher Education, 14(1), 71-80.

[3] Berger, P. \& Stripling, B. (2010). Student inquiry and Web 2.0. School Library Monthly, Greenwood Publishing Group Inc. Vol XXVI, Vol. 5, Jan.

http://www.schoollibrarymonthly.com/articles/Berger2010 -v26n5p14.html (8 March 2011).

[4] Golding, C. (2011). Positioning interdisciplinary graduate research: (or how to avoid painful misunderstandings with your supervisors and examiners). Traffic [Parkville] 12 (2010): 17+Academic OneFile. Web. 2 Feb. 2011.

[5] Greenhow, C. (2009). Social scholarship: Applying social networking technologies to research practices. Knowledge Quest, American Library Association.

[6] Gross K. \& Myrka A. (2009). 'Roving' Interdisciplinary Professors. The Chronicle of Higher Education 55.20 (2009). Academic OneFile. Web. 2 Feb. 2011.

[7] Hauser, J. (2007). Media specialist can learn Web 2.0 tools to make school more cool. Computers in Libraries, Information Today Inc. Feb.

[8] Higbee J.L., Schultz J. L. \& Goff E., (2010). Pedagogy of inclusion: Integrated multicultural instructional design. Journal of College Reading and Learning 41.1 (2010): 49+ Academic OneFile. Web. 2 Feb. 2011.

[9] Johnson, A. K. (2011). Globalization from below: Using the internet to internationalize social work education. Journal of Social Work Education 35.3 (1999): 377. Academic OneFile. Web 2 Feb. 2011. 
[10] Kruck, S.E., \& Teer, F.P. (2009). Interdisciplinary student teams projects: A case study. Journal of Information Systems Education 20.3 (2009): 325+. Academic OneFile. Web. 2 Feb. 2011.

[11] O’Brien D., Scharber C. (2010). Teaching old dogs new tricks: The luxury of digital abundance. Journal of Adolescent \& Adult Literacy, 53(7), April.

[12] VoiceThread (2011). http://www.voicethread.com (8 March 2011).

[13] Valenza, J. K., Johnson, D. (2009). Things that keep us up at night. School Library Journal, Reed Business Information, a division of Reed Elsevier, Inc. Oct. Access date: 9 May, 2010 http://ijea.asu.edu/v8n8.

[14] Yan, J. (2008). Social technology as a new medium in the classroom. New England Journal of Higher Education, New England Board of Higher Education, Winter.

[15] Zalanga, S. (2009). Interdisciplinary studies and scholarship: Issues, challenges, and implications for 'Third World" development and social change. Human Architecture: Journal of the Sociology of Self-Knowledge 7.3 (2009): 57+. Academic OneFile. Web. 2 Feb. 2001. 